\title{
Research on the Path of Rural Economic Transformation under the Background of Urbanization: A Case Study of Mucun Town
}

\author{
Caixia Liu \\ Southwest Minzu University, Chengdu, China \\ Email: 840764321@qq.com
}

How to cite this paper: Liu, C.X. (2019) Research on the Path of Rural Economic Transformation under the Background of Urbanization: A Case Study of Mucun Town. Open Access Library Journal, 6: e5823.

https://doi.org/10.4236/oalib.1105823

Received: September 29, 2019

Accepted: October 14, 2019

Published: October 17, 2019

Copyright $\odot 2019$ by author(s) and Open Access Library Inc.

This work is licensed under the Creative Commons Attribution International License (CC BY 4.0). http://creativecommons.org/licenses/by/4.0/

\section{Open Access}

\begin{abstract}
$\mathrm{Mu}$ Town belongs to Liulin County, Luliang City, Shanxi Province. It is a typical resource-based township economy developed by relying on coal resources. In recent years, the economic development of Liulin County is in a period of strength. According to the national rural revitalization strategy, the economic transformation of $\mathrm{Mu}$ villages and towns is imminent. Based on the analysis of the current economic and social development in Mucun town, this paper focuses on the transformation of coal industry, and explores how to integrate resources and realize economic transformation in the process of urbanization in Mucun town in combination with its transformation ideas in agricultural development, resource development, ecological environment and regional development.
\end{abstract}

\section{Subject Areas}

Business Analysis, Development Economics

\section{Keywords}

Urbanization, Rural Economy, Transformation Path, Mucun Town

\section{Introduction}

The 19th National Congress of the Communist Party of China (CPC) put forward that the implementation of the rural revitalization strategy is an important measure to realize the goal of "two hundred years". The implementation of the rural revitalization strategy will be the basic orientation of theoretical innovation, decision-making, policy implementation and government work in the future "three rural" areas. The report depicts the future rural prospect of "pros- 
perous industry, livable ecology, civilized rural customs, effective governance and rich life". It can be seen that rural revitalization is not only an important battlefield for China to build a modern and powerful country, but also determines the quality of the "Chinese dream" to a great extent [1].

Based on the analysis of the current economic development situation in $\mathrm{Mu}$ cun town, this paper focuses on the transformation of the coal industry, combines Mucun's transformation ideas in agricultural development, resource development, ecological environment and regional development, and explores how to integrate resources and realize economic transformation in the process of urbanization through questionnaire survey.

\section{Research Background and Plan}

\subsection{Overview of Mucun Town}

$\mathrm{Mu}$ Town is located in the hinterland of Liulin County, with geographic coordinates between 110 52'30.7" east longitude and 37 23'30.5" north latitude. National Highway 307, Fenjun Expressway and Taizhongyin Railway pass through the town. The maximum distance between east and west of the border is 6 kilometers, the maximum distance between north and south is 10 kilometers, and the total area is 36.75 square kilometers. It is 5 kilometers to the east from Liulin County and 30 kilometers to Luliang City. The town has a total of 8114 households and a total population of 24,206, including 19,367 in agriculture, 4839 in non-agriculture and 12,012 in labor force, of which 6722 are men, accounting for $55.96 \%$. There were 5290 women, accounting for $44.04 \%$. The population density is 917.06 people per square kilometer (2012) [2].

Mucun Town is located in the loess hilly and gully region. The terrain in the territory is high in the north and low in the south, with ridges and ravines crisscrossing. The landform type is divided into hills. The middle zone is narrow and flat, with an average altitude of about 610 meters. Mucun Town is rich in underground resources, mainly storing 4\# high-quality coking coal, 5\# and 9\# coal seams and gas, which are known as "national treasures". Crops are mainly sorghum, corn, cotton, wheat, buckwheat and other minor cereals. Economic crops in paddy fields include red garlic, indigo and Chinese cabbage.

The superior geographical environment, traffic conditions and underground resources have attracted the presence of two major state-owned enterprises, $\mathrm{Hu}$ ajin Coking Coal Company and Liulin Power Plant, which have driven the rapid economic development of $\mathrm{Mu}$ Village, which has become one of the wealthier villages and towns in the county. In recent decades, due to the extensive mode of economic growth, the resources and environmental costs consumed by the development of the coal industry have increased rapidly, and the sustainable development faces many obstacles [3].

\subsection{Sampling and Sample Composition}

Mu Town has 9 administrative villages and 18 natural villages. Among them, Du 
$\mathrm{Yu}$ and Zhang Jiashan have no primary and secondary schools, and the resident population is mostly preschool children and middle-aged and elderly people, mainly engaged in agriculture and animal husbandry. Therefore, the scope of our investigation excludes these two administrative villages. According to the principle of stratified and classified sampling, we selected a total of 50 families as the household survey objects, and selected 50 people as the main survey objects. The age of the survey objects is limited to 18 - 70 years old.

\subsection{Questionnaire Structure and Survey Methods}

The survey uses a combination of closed and open questionnaires. Closed means that the setting of questions, options and indicators is established, and the subjects only need to make choices within a given range. The last two "opinions on tourism in ancient towns" and "suggestions on economic construction in hometown" are open questions, which are subjectively stated by the respondents. The one-to-one method of investigation is adopted, i.e. the investigators ask questions one by one, the subjects answer, and the investigators circle or fill in. The investigator is the author himself.

\section{The Current Situation of Economic and Social Development in Mu Villages and Towns}

There are 12 enterprises in Mucun Town, including 2 state-owned enterprises, namely Huajin Coking Coal Company and Liulin Power Plant. Kangjiagou Coal Mine was merged and integrated into Tongde Coking Coal Company; There are 3 coal washeries, 2 brick factories, 3 gas stations, 1 liquefied gas station and 1 construction company (Hongyuan Construction Company).

By sorting out the statistical questionnaire data, the author found that the economic and social development of Mucun Town mainly has the following characteristics:

\subsection{Basic Information}

The ratio of agricultural population to non-agricultural population in Mucun town is about 5:1, but the per capita area of land is only $0.3 \mathrm{mu}$, and the income from agricultural products can basically maintain the life of the family. Every family mainly depends on men for its financial resources, and most women are mainly responsible for family life and children's education. The resident population of each family is mostly about 5 , and each family has about 3 children. The parents' education level is relatively low, with nearly $80 \%$ of them being primary school or below, $16 \%$ being junior high school or above, and $4 \%$ being senior high school or above. Compared with their parents, their children's overall educational level has been greatly improved. Most families adhere to the educational aim of "knowledge changes fate" and attach more importance to their children's education. The annual income of each family is mostly in the range of 20,000 to 30,000 and 30,000 to 50,000, and the annual income of double-working families 
can reach more than 50,000. The annual income of households has been growing slowly in the past ten years, while the previous households engaged in the coal industry showed a decrease in annual income.

\subsection{Township Policy and Spiritual Life}

The implementation of the agricultural policy in Mucun town is not in place. $72 \%$ of the villagers think that the township cadres have not led the masses to become rich. The subjects (male, 46 years old) said: "since the land was expropriated for the second phase of the power plant project, there is less land in the family, only enough vegetables can be grown for themselves, and there is no way out for farming. However, they do not know what they can do to earn money. The neighbors who saw the vegetable market grow and sell themselves could not sell a few dollars. I don't know if we can modernize our agriculture and cultivate it in large quantities. We should not only plant three parts of our own land, but also be tired and have no harvest." $70 \%$ of the villagers remained silent on the development of villages and towns and the democratic election of cadres in villages and towns. The subjects (female, 53) said: “it's the same who is the leader. he only cares about his own interests and has no sense of overall situation. he gives advice for the economic development of the whole town." It can be seen that villagers have certain negative emotions about the implementation of relevant policies and have no confidence in the future development of villages and towns. In terms of medical treatment and pension reimbursement, there has been a great improvement in the past ten years, and the subjects are highly satisfied.

In leisure time, the main activities of villagers are: playing mobile phone $30 \%$, watching TV 41\%, playing mahjong 19\%, reading books, newspapers and magazines 7\%, and other activities 3\%. Most middle-aged subjects like watching anti-Japanese movies and TV programs, and most of them talk about "Biography of luliang heroes" with relish. The rest of the middle-aged subjects took playing mahjong as their main pastime. It didn't matter whether they won or lost. They sat together and chatted while playing happily. Most young people like to play mobile phones, especially playing games and fast hands. The subjects (male, popular science worker, 72 years old) thought: “The villagers are less concerned about current affairs and politics, and are unwilling to study and study technology in their spare time. As a result, most people have less knowledge, no feelings of family and country, muddle along and cannot keep pace with the times."

\subsection{Township Infrastructure}

In the past ten years, the biggest change in the material life of $\mathrm{Mu}$ villages and towns is "living". Every family has renovated their houses, built high-rise buildings and improved their living environment. However, due to the lack of development planning, there are many problems in the overall village pattern and rural roads. In the past, the open-air dry toilets of every household were also reformed as a whole. The government funded the construction of public toilets, 
washed them with water, and equipped special personnel to clean them. They were clean, environmentally friendly and hygienic.

According to the official of the township government, the 307 national highway crossing the township has only two lanes and cannot meet the traffic demand. The county party Committee has sent a team of workers to divert the national highway so as to alleviate the noise and air pollution of the surrounding residents. However, the funds have not been in place and the team can only stand by.

At present, there is no special cultural activity center and fitness center in the town, which is largely related to the local people's ideas. Almost all the middle-aged and elderly women in the survey were ashamed to dance in public. In addition, most of the subjects had no interest in singing, writing or drawing. This may also be the reason why the government did not pay for the construction of related sites.

\subsection{Expectations for the Future Development of Villages and Towns}

Villagers also have a lot of feelings about the development and changes of villages and towns in recent years, and put forward some of their own ideas, mainly as follows: I hope village cadres can really do practical things and seek development for the villagers; The policies of the superior departments are put in place and the tourism development and construction of ancient towns are planned reasonably. To explore a road suitable for the social and economic development of $\mathrm{Mu}$ villages and towns, and villagers to participate in the common prosperity independently; Promote the construction of infrastructure in villages and towns, strengthen the construction of cultural life, and enrich leisure and entertainment places; Strengthen the construction of greening, improve the environment, and rationally dispose of garbage and waste.

$90 \%$ of the villagers think that the era of relying on coal to develop economy is over, and hope the government will develop Mucun ancient town with them to realize economic transformation. The subjects (male, 54 years old) believed: "Coal mining has made a historic contribution to the economic development of $\mathrm{Mu}$ Village. While coal brings huge economic benefits, it also brings serious environmental pollution, water quality destruction, soil erosion and other problems." Obviously, extensive exploitation that relies too much on resources is not a long-term solution. We must resolutely promote economic transformation.

\section{Mucun Economic Development Problems}

\subsection{The Economic Development Mode Is Single and the Economic Structure Is Unreasonable}

For a long time, people have been blindly exploiting coal resources. They have no long-term thinking about the nonrenewability of resources and have not explored new development models. The economic development mode is single, and about $80 \%$ of the fiscal revenue should be obtained from coal. As a result, 
the gap between the rich and the poor in the region has widened and house prices have risen. However, income has not risen correspondingly. On the contrary, the depression in the coal industry has made life difficult for ordinary people.

\subsection{The Ecological Environment Deteriorated and the Air Quality Declined}

Due to the uncontrolled mining in the past, burning coal for heating and power generation has caused serious environmental pollution and air quality decline. At the same time, 307 national highway was built, all the trees on both sides of the road were cut down and the greening was seriously damaged. As Mu Village has a continental climate of warm temperate zone, with less rain and more wind, when it is windy, dust is flying everywhere and it is impossible to go out. The whole township is in a black sand. In winter, every big boiler uses coal as its main fuel, and thick smoke billows from its chimneys.

\subsection{The Pressure on Employment Has Increased and the Number of Unemployed Has Increased}

In recent years, the depression of the coal market and the closure of coal mines have caused many people to lose their jobs. Some people choose to work outside the country and some people are unemployed at home. Through household surveys and interviews, nearly $85 \%$ of the local personnel engaged in the coal mine industry have not attended college and have not received professional technical training. Many people have also expressed their reluctance to work outside the country and are accustomed to local life. As they have no higher education, their ideas are relatively backward. A large number of people are unemployed at home, which has greatly impacted the local economic development.

\subsection{The Traditional Culture Is Desalinated and the Development of Ancient Towns Lags Behind}

$\mathrm{Mu}$ Village is an ancient town with a history of 500 years. The ancestors who lived here were famous in Shanxi and Shaanxi for their farming and reading, flourishing etiquette and simple folk customs. It has a strong historical culture and folk culture. During the Ming and Qing dynasties, the three families of Wang, Liu and Jia were the most famous businessmen in western Shanxi. A street in Mu Village in Ming and Qing Dynasties is the most complete ancient architectural complex preserved by Liulin at present, and it is the great spiritual wealth of Mu Village people.

With the development of the society, the local people do not pay enough attention to the traditional culture. Some folk customs gradually disappear without successors and cannot be well inherited and protected. In particular, a street in the Ming and Qing Dynasties in Mu Village was included in the tourism development plan of the ancient town as early as 2014, but it has not yet formed a scale and there is no special person in charge of the project. It is particularly 
important to develop tourism in ancient towns and attach importance to the protection and development of traditional cultural resources.

\section{Discussion on the Path of Economic Transformation in Mucun Town}

Under the background of national policies and urbanization, Mucun's economic development needs to be transformed to meet the needs of social development, solve the problem of food and clothing for the people, and strive to achieve the goal of a well-off society for all. After investigation and study, the author puts forward the following suggestions.

\subsection{Adjust and Optimize the Industrial Structure and Establish a Diversified Modern Industrial System}

Coal enterprises should increase investment in science and technology and stick to a scientific and intensive road. Implement the strategy of "coal-based, diversified development", extend the coal industry chain and take the road of intensive development [4]. According to the requirements of sustainable development, when coal resources are exhausted, coal mining should be carried out in a timely manner to make a good strategic reserve of coal resources. Mu Village should further strengthen the transformation and upgrading of traditional industries and the cultivation and expansion of emerging industries, cultivate new economic growth points, gradually establish a diversified modern industrial system, and gradually reduce its dependence on the resource sector. On the other hand, Mucun's industrial transformation should take the development of emerging industries as a breakthrough to accelerate the transformation of development power to high-tech industries and modern service industries.

\subsection{Actively Develop Green Industries and Promote Energy Conservation and Emission Reduction in the Industrial Field}

Mucun's economic transformation should pay more attention to green development, vigorously develop circular economy and implement energy conservation and emission reduction. Take circular economy as the main means to transform and upgrade traditional industries, and actively promote the circular development of traditional industrial economy. Pay attention to the protection of ecological environment, villages and towns adopt collective heating and other methods to reduce pollutant emissions. Using economic, technological, legal and necessary administrative means, we will step up efforts to promote energy conservation, emission reduction and comprehensive utilization of resources in the industrial field, improve the ecological compensation mechanism, and develop recycling.

\subsection{Create a Brand of Characteristic Agricultural Products and Vigorously Develop the Market Environment}

In terms of policies, we should increase investment in agriculture and develop 
infrastructure construction for farmland and water conservancy, such as paddy field cash crops red garlic, indigo and Chinese cabbage. At the same time, make full use of local geographical advantages and resource conditions, timely adjust the agricultural planting structure, develop characteristic agriculture, give priority to sorghum, corn, cotton, wheat, buckwheat and other minor cereals, vigorously implement the strategy of promoting agriculture through science and technology, through the promotion of fine seeds, formula fertilization and plastic film mulching and other new agricultural technologies, carry out scientific knowledge training for farmers, guide farmers to cultivate fields scientifically, and promote agricultural production towards intensive management.

\subsection{Pay Attention to the Protection and Development of Traditional Cultural Resources and Develop Tourism in Ancient Towns}

Liu Lin's "plate culture" has a long history and rich value and is listed as a national intangible cultural heritage. There are also unique cultural activities such as "Umbrella Head Yangko" and "Willow Woods Playing and Singing", which have a strong flavor of the Loess Plateau. The protection and development of these cultural heritage, the formation of large-scale tourism projects can not only protect traditional culture but also have a very big role in promoting local economy. The service industry has a good momentum of development, and the sesame cake market of $\mathrm{Mu}$ Village "Lao Yan Jia" featuring Liulin sesame cake has great development potential. To develop cultural tourism in Mucun ancient town, to attract overseas personnel to visit and travel there, to experience folk customs, to excavate local traditional culture and handicraft products, and to explore diversified economic development paths. At the same time, it provides local people with employment opportunities, participates in the local economic construction together, and makes suggestions for the development of Mu Village.

\section{Conclusion}

The Central Rural Work Conference proposed that in order to take the road of revitalizing the socialist countryside with Chinese characteristics, we must adhere to the harmonious coexistence of man and nature and take the road of green development in the countryside. Under the background that the country promotes the overall planning of urban and rural development and the overall construction of a socialist harmonious society, it is particularly important to speed up the economic transformation of resource-based cities and adopt a diversified and intensive friendly circular development mode to realize the sustainable development of economy and urban and rural areas. In a word, Mu Village and Town should, in the process of transformation, firstly, optimize the pillar industry from the reality, save energy and reduce emissions, and make it bigger,better and stronger through technological improvement and innovation. Second, the government's policy is inclined to increase investment in the tertiary 
industry to develop tourism in ancient towns and protect traditional culture. Third,pay attention to the protection of the ecological environment, do a good job in pollutant discharge treatment, domestic waste has a home to return to. Fourth, the local farmers should change their ideas, accept new things and pass on the fine traditional culture at the same time, so as to be good successors for the development of Mu Village economy.

\section{Fund Project}

The innovative research project of postgraduate students of Southwest Minzu University for Nationalities "Research on the Path of Rural Economic Transformation under the Background of Urbanization: A Case Study of Mucun Town" is funded (CX2019SZ161).

\section{Author's Brief Introduction}

Liu Caixia (1993-), female, native of Liulin Mu Village, Shanxi Province, master's degree candidate of 2018 from Southwest Institute for Nationalities, Southwest Minzu University, research direction: issues related to rural economy, ethnic economy and tourism industry.

\section{Conflicts of Interest}

The author declares no conflicts of interest regarding the publication of this paper.

\section{References}

[1] Liu, S.Y. and Xiong, X.F. (2018) Implementation of China's Rural Revitalization Strategy and Institutional Supply. Political Economy Review, 9, 80-96.

[2] Wei, Y.P. (2014) Township Records of Liulin County, Shi Zhiban of Liulin County. Government information.

[3] Fu, W.L. (2014) Discussion on Transformation Path of Resource-Based City-Taking xiaoyi City as an Example. School of Economics and Management, Shanxi University, Taiyuan.

[4] Yang, D. (2015) Predicament and Outlet for Coal Enterprises to Drive New Urbanization Development Mode-An Investigation of Characteristic Agricultural Park in Liulin County, Shanxi. China's Collective Economy, No. 25, 6-7. 


\section{Appendix: Household Survey Questionnaire for Mucun Town}

I. Basic Information (Please mark " $\checkmark$ " under the item label that meets your conditions)

1) Gender: A. male B. female

Where do you come from: A. city B. countryside

2) Age: A. 18 - 35 years old B. 35 - 50 years old C. 50 - 60 years old D. over 60 years old

3) Your educational level: A. primary school and below B. junior high school

C. high school (including technical secondary school) D. junior college or above

4) Your political outlook: A. communist party member B. communist youth league member $\mathrm{C}$. democratic party D. masses

5) The resident population of your family: A. 1 B. 2 C. 3 D. 4 E. 5 F. 6 or more

6) Your current annual household income: A. less than 5000 RMB B. 5000 10,000 RMB C. 10,000 - 20,000 RMB D. 20,000 - 30,000 RMB E. 30,000 - 50,000 RMB F. more than 50,000 RMB

II. The content of the survey (please mark " $\checkmark$ " under the item number that conforms to your opinion)

7) Changes in Family Annual Income in Recent Ten Years

A. increase by more than 20,000

B. increase by 10,000 to 20,000

C. increase by less than 10,000

D. no change or decrease

8) What do you think has changed most in material life in the past ten years?

A. Clothing B. food C. living D. travel E. education F. recreation G. salary

9) What do you think of the overall implementation of the county's agricultural policy?

A. better B. general C. poorer D. very poor

10) What is your attitude towards the election of village cadres?

A. very active, must participate in B. more active, generally participate in

C. not very active, occasionally attend D. never attend, boring

11) What do you think is the implementation of democratic election procedures in Mucun Town?

A. very normal B. basically normal C. there is a phenomenon of monitoring voters to write votes.

D. the phenomenon of falsification of election results E. canvassing and bribery

F. compulsory elections

12) What is your main source of income?

A. income from agricultural products B. aquaculture C. household sideline D. income from local rural enterprises

E. go out to work F. own enterprise G. other 
13) What are the main items of your household expenditure? (Optional Three)

A. children's marriage B. children's education C. medical D. house

E. car purchase F. family daily expenses G. purchase of means of production

14) Compared with the past ten years, the economic situation of your village...

A. improve a lot B. improve a little C. no obvious change D. not as good as in the past

15) What do you think is the place where the economy of Mucun Town has improved the most?

A. transportation facilities B. housing conditions (including the convenience of water and electricity)

C. household appliances D. household or agricultural vehicles E. children's education

16) What do you think are the main obstacles to the future economic development of Mucun Town?

A. labor shortage, young people working in cities B. lack of national policy support

C. lack of qualified personnel D. inconvenient transportation

17) What do you do in your spare time after working?

A. watching TV B. reading books, newspapers and magazines C. playing cards and mahjong

D. learning and studying techniques E. activities

18) What do you think has brought the greatest convenience in the past ten years is "multi-topic selection"

A. improvement of medical insurance and old-age insurance

B. new rural transportation construction

C. the new rural agriculture of science and technology

D. continuous increase and expansion of factories

E. remission of education tuition

F. other

19) Are you satisfied with rural cultural life?

A. satisfied B. not satisfied C. not satisfied

$20)$ Is there a cultural activity center in your village?

A. yes B. no C. unclear

21) Do you think township party and government leaders attach importance to rural cultural work?

A. attach importance to B. attach more importance to C. general D. do not attach importance to E. do not understand

22) What do you think are the problems that need to be solved urgently in the construction of rural culture? [Multi-Topic Selection]

A. increase the construction of cultural facilities $B$, guide all kinds of sports activities C. strengthen the construction of cultural backbone team

D. developing rural characteristic culture E. increasing government funding 
23) What do you think of your neighborhood?

A. good B. good C. general D. bad

24) What do you think of the environmental sanitation situation in $\mathrm{Mu}$ Town?

A. beautiful B. average C. poor

25) Which of the following ways do you plan to solve your pension problem?

A, rely on children $B$, save money to prevent old age.

C. pension or pension D. other means

26) Is there any serious loss of arable land in your village?

A. no loss B. loss, less

C. more losses D. unclear

27) What do you think of the current social atmosphere in Mucun Town?

A. better B. general C. poorer D. very poor

28) What do you think are the main aspects that lead to disharmony in the social atmosphere in your hometown? [Multi-Topic Selection]

A. gambling B. theft C. illegal building D. violent disputes

E. superstitious activities F. bribery and bribery G. other

29) What do you think of the implementation of the government's social policy?

A. the people to benefit B. face project

C. insufficient implementation of grassroots publicity D. other

30) What do you think of the development of tourism in Mucun Town?

31) Do you have any suggestions for the economic construction of your hometown?

Thank you for your support and cooperation. I wish you and your family happiness! 